\title{
Follow up of premature babies treated with artificial surfactant (ALEC)
}

\author{
C J Morley, R Morley
}

\begin{abstract}
Of 235 survivors who had taken part in a randomised trial of artificial surfactant and who were born in Cambridge, follow up information was available for 231 (98\%) infants. In 12 cases information came from local doctors; all others were assessed at 9 and 18 months $(n=212)$ or 9 months only $(n=7)$. There was no difference between those who had been treated with surfactant and control babies in the incidence of neurological impairment, mental impairment, respiratory infections, allergies, or hospital admissions up to 18 months after full term. In those born before 30 weeks' gestation (where surfactant most improves survival) the number of surviving randomised children who were normal was $\mathbf{3 5}$ of $\mathbf{6 1}$ in the treated group (57\%) compared with 25 of 61 in the control group (41\%). Improved neonatal survival after prophylactic surfactant treatment is not associated with an increased incidence of neurodevelopmental impairment.
\end{abstract}

Artificial surfactant (artificial lung expanding compound, Pumactant, Britannia Pharmaceuticals) composed of dipalmitoylphosphatidylcholine and unsaturated phosphatidylglycerol in a ratio of 7:3 has been used successfully in one case controlled study ${ }^{12}$ and two randomised control trials. ${ }^{34}$ In the last of these, a multicentre trial, a reduction in neonatal mortality for babies between 25 and 29 weeks' gestation, from $27 \%$ to $14 \%$ was shown. There was also a reduction of one third in the incidence of parenchymal brain haemorrhages from $24 \%$ to $16 \%$, and a significant reduction in the need for more than $30 \%$ oxygen and the amount of artificial ventilation required. There has been concern that improved survival of these very premature babies may result in an increased number of impaired children. This trial presents the follow up of the survivors treated in Cambridge from the first randomised trial. ${ }^{3}$

Department of Paediatrics, Level 8, Addenbrooke's Hospital, Hills Road, Cambridge CB2 $2 Q Q$

C J Morley

Medical Research Council Dunn Nutrition Unit, Cambridge R Morley

Correspondence to: Dr C J Morley.

Accepted 26 Nacich 1990

\section{Patients and methods}

All surviving children from the trial were invited for follow up examinations by RM 9 and 18 months after their expected date of delivery. The examiner did not know any details about the infants' neonatal progress, nor whether they had been randomised to receive treatment with surfactant or to be controls. At 9 months a medical history and full physical examination were undertaken, including the neurological examination described by Amiel-Tisson and
Grenier. ${ }^{5}$ The developmental screening inventory described by Knobloch et al was also used. ${ }^{6}$ The score for each area of development was derived from the child's age corrected for prematurity (that is, chronological age minus the time from delivery to expected date of delivery). An overall development quotient was calculated as the mean of the quotients for the five individual areas (adaptive, motor, fine motor, language, and personal/social).

At 18 months a history was taken and the child had another physical examination. The Bayley mental and motor scales were administered and the mental development index and psychomotor development index calculated. ${ }^{7}$ The mental scale, like most tests of intellectual development in small children, relies heavily on fine motor skills appropriate for age. In children with cerebral palsy, therefore, the results often bear little relation to intellectual prowess. The academic scale of Developmental Profile II $^{8}$ for which an intelligence quotient (IQ) equivalent can be calculated relies little on fine motor skills at this age, so it was used for all infants in addition to the Bayley mental scale. Scores for all these tests were also calculated for the age corrected for prematurity. Mental impairment was diagnosed when the child's score was more than two standard deviations below the population mean. Social class of the family was coded using the Registrar General's classification, social class III being subdivided into nonmanual and manual. ${ }^{9}$ The child's rank was recorded as his birth order in the living children in the family, with twins assigned equal rank.

Student's $t$ test, the $\chi^{2}$ test, and linear regression were used for statistical analysis of the results.

\section{Results}

Of 276 eligible infants included in the surfactant trial, 244 (119 controls and 125 treated with surfactant) survived to leave the neonatal unit. Nine of these infants died later, five controls (two of chronic lung disease, one of sudden infant death sydrome (SIDS), one of Wilms' tumour, and one of toxic shock syndrome), and four treated with surfactant (three of chronic lung disease, and one of SIDS). There were 235 babies eligible for follow up. Four were lost to follow up: all were children whose parents had been posted overseas. They were all girls and included one control and three who had been treated with surfactant; none were born at less than 30 weeks' gestation. It was not known whether they survived. In total, 231 infants were known to survive to 18 months after full 
term: 114 controls (54 boys) and 117 treated with surfactant (58 boys). Of these, 212 (92\%) were seen at 18 months: 107 controls and 105 treated with surfactant; a further seven were only seen at 9 months, before they moved from the area; thus $219(95 \%)$ were seen and examined by RM. The remaining 12 children (six in each group) had left the area, but information on their developmental and neurological prowess was obtained from their local doctors.

\section{CHILDREN BORN AT LESS THAN 30 WEEKS' GESTATION}

Of the 122 infants born at less than 30 weeks' gestation who entered the trial (61 in each group) there were 85 survivors who were all seen or reported on at 18 months ( 47 treated and 38 controls).

OUTCOME OF CHILDREN NOT SEEN AT FOLLOW UP Ten of the 12 children who were not seen by RM were reported to be developmentally normal (five in each group): of the other two, one (a control) was reported to have mild spastic diplegia but not mental impairment and the other (a treated baby) was microcephalic and mentally impaired.

OUTCOME OF CHILDREN SEEN ONLY AT 9 MONTHS Of the seven infants seen only at 9 months, six had developmental quotients well within the normal range; they were reported as developmentally normal at 18 months. One, a control infant, had Prader-Willi syndrome and was mentally impaired; he was excluded from analysis of mental impairment as his impairment was the result of a recognised congenital abnormality.

\section{NEUROLOGICAL OUTCOME}

Twenty three children were diagnosed as having neurological impairment: nine of 114 were controls (8\%) and 14 of 117 had been treated with surfactant $(12 \%)$.

Among the infants of less than 30 weeks' gestation, neurological impairment was diagnosed in six of 38 controls (16\%) and nine of 47 treated infants (19\%), and in those of 30 weeks' gestation or more the incidence was three of 76 among the controls (4\%) and five of 70 in the treated infants $(7 \%)$. There was no significant difference between treated and control children.

Severity of impairment was assessed functionally. Thus children not able to sit unsup- ported at 18 months were classified as 'severely impaired', those not able to pull up to standing or walk with hands held as 'moderately impaired', and those able to do all these things but having abnormal neurological signs as 'mildly impaired'. In the control group impairments were: severe $(n=4)$, moderate $(n=1)$, mild $(n=4)$, compared with severe $(n=7)$, moderate $(n=2)$, and mild $(n=5)$ in the treated group. In the babies born before 30 weeks' gestation the impairments were: severe $(n=3)$, moderate $(n=1)$, mild $(n=2)$ among the controls, and severe $(n=5)$, moderate $(n=1)$, mild $(n=3)$ in those who were treated.

\section{DEVELOPMENTAL OUTCOME}

Mean scores for the Bayley mental scale, Bayley motor scale and academic scale of Developmental Profile II (IQ equivalent) are shown in table 1. These results are for the 212 infants seen by RM at 18 months after full term. There are no significant differences between the mean scores of children from control and treated groups for the whole cohort or for the babies of less than $\mathbf{3 0}$ weeks' gestation.

Developmental outcome is considerably influenced by social and demographic factors. To be certain that any minor imbalances were not biasing the results, the scores for all infants were entered into multiple regression analysis as dependent variables. Independent factors included in the models were treatment with surfactant and pre-existing factors at randomisation: sex, gestation, social class, and birth rank. The results confirmed that surfactant treatment was not significantly related to the Bayley mental scale, IQ equivalent, or Bayley motor scale in the whole group or in those above and below 30 weeks' gestation, whether or not children with neurological impairment were included.

In neurologically normal infants, five of 105 controls $(5 \%)$ controls were diagnosed as mentally impaired (Bayley mental development index $>70$ in those tested by $R M$ ) compared with four of 103 treated infants $(4 \%)$. The incidence in babies of less than 30 weeks' gestation was three of 38 controls (8\%) and two of 47 treated babies (4\%).

\section{NORMAL SURVIVAL IN BABIES BORN AT LESS THAN} 30 WEEKS' GESTATION

In the surviving children born before 30 weeks' gestation, in whom mortality was significantly reduced by prophylactic treatment with artificial surfactant (ALEC), treated children had no

Table 1 Mean $(S D)$ developmental score for control and surfactant treated groups at 18 months after full term. Results are shown for all children, and subdivided at 30 weeks' gestation

\begin{tabular}{|c|c|c|c|c|c|c|}
\hline & \multicolumn{2}{|l|}{$\begin{array}{l}\text { All } \\
\text { infants }\end{array}$} & \multicolumn{2}{|c|}{$\begin{array}{l}\text { Infants of }<30 \text { weeks' } \\
\text { gestation }\end{array}$} & \multicolumn{2}{|c|}{$\begin{array}{l}\text { Infants of } \geqslant 30 \text { weeks' } \\
\text { gestation }\end{array}$} \\
\hline & $\begin{array}{l}\text { Controls } \\
(n=107)\end{array}$ & $\begin{array}{l}\text { Surfactant } \\
(n=105)\end{array}$ & $\begin{array}{l}\text { Controls } \\
(n=73)\end{array}$ & $\begin{array}{l}\text { Surfactant } \\
(n=64)\end{array}$ & $\begin{array}{l}\text { Controls } \\
(n=34)\end{array}$ & $\begin{array}{l}\text { Surfactant } \\
(n=41)\end{array}$ \\
\hline $\begin{array}{l}\text { Bayley mental development index* } \\
\text { IQ equivalent } \\
\text { Bayley motor development index* }\end{array}$ & $\begin{array}{r}104(21) \\
107(18) \\
93(16)\end{array}$ & $\begin{array}{r}101(18) \\
105(19) \\
93(15)\end{array}$ & $\begin{array}{r}97(20) \\
102(17) \\
88(19)\end{array}$ & $\begin{array}{r}95(19) \\
100(19) \\
90(15)\end{array}$ & $\begin{array}{r}107(20) \\
109(19) \\
95(14)\end{array}$ & $\begin{array}{r}103(17) \\
109(18) \\
95(14)\end{array}$ \\
\hline
\end{tabular}

${ }^{*}$ Scores for children with neurological impairment are excluded. 
Table 2 Outcome of infants of less than 30 weeks' gestation

\begin{tabular}{lcc}
\hline & $\begin{array}{c}\text { Control } \\
(n=61)\end{array}$ & $\begin{array}{l}\text { Surfactant } \\
(n=61)\end{array}$ \\
\hline Neonatal deaths & 20 & 10 \\
Late deaths & 3 & 4 \\
Neurological impairment & 6 & 9 \\
Mental impairment* & 3 & 2 \\
Hearing loss only* & 4 & 1 \\
Normal survivors & $25(41 \%)$ & $35(57 \%)$
\end{tabular}

*Those who also had neurological impairment are not included here.

Table 3 Number (\%) of problems encountered after leaving the neonatal unit (only those seen by $R M$ are included)

\begin{tabular}{|c|c|c|c|c|}
\hline & \multicolumn{2}{|c|}{ All infants } & \multicolumn{2}{|c|}{ Infants of $<30$ weeks' gestation } \\
\hline & $\begin{array}{l}\text { Control } \\
(n=107)\end{array}$ & $\begin{array}{l}\text { Surfactant } \\
(n=105)\end{array}$ & $\begin{array}{l}\text { Control } \\
(n=34)\end{array}$ & $\begin{array}{l}\text { Surfactant } \\
(n=4 I)\end{array}$ \\
\hline $\begin{array}{l}\text { Respiratory infections* } \\
\text { Hearing loss } \\
\text { Otitis media } \\
\text { Hospital admissions† for: }\end{array}$ & $\begin{array}{c}50(47) \\
9(8) \\
41(38)\end{array}$ & $\begin{array}{l}57(54) \\
4(4) \\
45(43)\end{array}$ & $\begin{array}{r}19(56) \\
6(18) \\
17(50)\end{array}$ & $\begin{array}{l}27(66) \\
2(5) \\
20(49)\end{array}$ \\
\hline $\begin{array}{l}\text { Operations } \\
\text { Respiratory infections } \\
\text { All causes }\end{array}$ & $\begin{array}{l}13(12) \\
9(8) \\
44(41)\end{array}$ & $\begin{array}{l}14(13) \\
10(10) \\
46(44)\end{array}$ & $\begin{array}{r}7(21) \\
4(12) \\
21(62)\end{array}$ & $\begin{array}{l}7(17) \\
5(12) \\
19(46)\end{array}$ \\
\hline
\end{tabular}

Some children had more than one admission.

*The number of children with one or more infections diagnosed and treated by a doctor. tThe number of children who had one or more admissions.

increase in the incidence of physical or mental impairment, or of hearing loss. Table 2 shows the outcome for all infants under 30 weeks' gestation who were randomised in Cambridge. Follow up information was complete for this group. Of 61 children randomised to each group, there were 25 unimpaired survivors in the control group (41\%), compared with 35 in the group treated with surfactant $(57 \%)$. The $95 \%$ confidence interval for an improved rate of normal survival was -1 to $33 / 100$.

\section{OTHER MEDICAL PROBLEMS}

The incidence of respiratory infections after discharge from the neonatal unit, episodes of otitis media, hospital admissions, and operations did not differ significantly between the control and treated groups (table 3 ). There were no other significant differences between the control and treated infants. Food intolerance was reported by the mothers in 13 of those treated with surfactant $(11 \%)$, and 12 control infants (11\%). Two mothers from each group suspected that their child was allergic to eggs (the artificial surfactant contains egg lecithin). Three cases of mild wheezing were reported in the treated group (3\%), compared with six mild cases and one severe case (diagnosed as asthma) in the control infants $(6 \%)$. Mild infantile eczema was seen in 13 treated $(11 \%)$ and 11 control infants (10\%).

\section{Discussion}

Three trials of this surfactant have shown reductions in neonatal mortality and the incidence of brain haemorrhages. ${ }^{1-4}$ As such premature babies are at high risk of neurological or mental impairment, we were concerned that the increased survival of those very premature babies who were treated could lead to an increase in the number of impaired survivors.

Our data, like those of Vaucher et $a l^{10}$ and Halliday $e t a l,{ }^{11}$ have shown no increase in the rate of neurological or mental impairment in those treated with surfactant. In those children born before 30 weeks' gestation (the group showing the greatest improvement in survival after treatment) the number of normal survivors was greater in the treated ( 35 of 61 ) than the control (25 of 61) group (table 2). This strong trend was however, not significant $\left(\chi^{2} 3 \cdot 29\right.$, $\mathbf{p}=0.07)$. Children in the treated group did not differ from controls in their later requirements for admission to hospital or treatment of respiratory or middle ear infections, nor in their incidence of allergic reactions.

Treatment of very premature infants with prophylactic artificial surfactant (ALEC), significantly improved neonatal mortality, with no increase in the rate of neurodevelopmental impairment, respiratory illness, or allergies.

We thank the Medical Research Council (Project No G 81049318A) and the University of Cambridge Baby Research Fund for and the University
financial support.

1 Morley CJ, Bangham AD, Miller N, Davis JA. Dry artificial surfactant and its effect on very premature babies. Lancet 1981;i:64-8.

2 Morley CJ. The Cambridge experience of artificial surfactant. In: Walters DV, Strang LB, Geubelle F, eds. Physiology and pathology of the fetal and neonatal lung. Lancaster: and pathology of the
MTP, 1987:241-53.

3 Morley CJ, Greenough A, Miller N, et al. Randomized trial of artificial surfactant (ALEC) given at birth to babies from 23 artificial surfactant (ALEC) given at birth to babies from

to 34 weeks gestation. Early Hum Dev 1988;17:41-54.
4 Morley CJ (for the Ten Centre Study Group). Ten centre trial of artificial surfactant (artificial lung expanding compound) in very premature babies. $\mathrm{Br} \mathrm{Med} \mathcal{F} 1987 ; 294: 991-6$.

5 Amiel-Tison C, Grenier A. Neurological assessment during the first year of life. Oxford: Oxford University Press, 1986.

6 Knobloch H, Pasamanick B, Sherard ES. A developmental screening inventory for infants. Pediatrics 1966;38:1095-8.

Bayley N. Bayley scales of infant development. New York: The Psychological Corporation, 1969.

8 Alpern GD, Boll TJ, Shearer MS. Developmental profile II. Aspen: Psychological Developmental Publications, 1980.

9 Office of Population Censuses and Surveys. Classification of occupations. London: HMSO, 1980.

10 Vaucher YE, Merritt TA, Hallman M, et al. Neurodevelopmental and respiratory outcome in early childhood after human surfactant treatment. Am J Dis Child 1988; 142:927-30.

11 Halliday HL, McClure G, McReid M. Growth and development two years after artificial surfactant replacement at birth. Early Hum Dev 1986;13:323-7. 